SEES Research Series

Research Article III

\title{
An Assessment of Used Oil Management among Mechanics in Linden, Guyana
}

Melinda Franklin, Patrick Ketwaru \& Denise Simmons

DOI: https://doi.org//0.52377/YDEK3267

\begin{abstract}
Environmental pollution that results from oil spills can be described as one of the most visible forms of pollution. Research has shown that a spill of used oil as little as one litre can contaminate as much as one million litres of freshwater. It is also one form of pollution in which the damages accrued can never really be valued in monetary terms. The absence of legislation governing the management of waste oil has resulted in management among waste oil generators being so poor that pollution has resulted. Although the Environmental Protection (Hazardous Waste Management) Regulations, 2000, of Guyana prohibits the improper disposal of hazardous waste, there is no formal system that allows for suitable disposal methods by outlining a safe method of doing so. The Regulations explicitly state that it does not apply to recovered oil and used oil filters. This research assessed the waste oil management practices among mechanics in Linden through the use of pre-tested questionnaires, with the aim of determining whether these practices were satisfactory. The overall practices were found to be generally poor since compliance with best practices for handling and disposal was well below $50 \%$ and contributed to unsatisfactory overall management practices.
\end{abstract}

Keywords: waste oil, mechanics, waste oil management

\section{Introduction}

Bourgeois (n.d., p. 2). indicated that waste oils represent the "greatest sources of pollution worldwide due to their multipurpose applications, quantities generated, low economic value and mismanagement". Although waste oil may be generated from a number of industries, the generation of waste oil from the automotive industry usually accounts for the largest volume generated in many parts of the world. According to the United States (US) Department of Energy, lubricating oil for use as automotive fluids accounted for approximately $59 \%$ of the total demand for lubricating oil in the United States (US Department of Energy, 2006). Similarly, in Guyana, 
waste oil generated from the sale, maintenance and repair of motor vehicles was responsible for the largest source of waste oil generation, accounting for $30.44 \%$ of the total waste oil generated (Caribbean Environmental Health Institute (CEHI), 2009, p. 44).

Impacts of Waste Oil

Waste oil is considered hazardous due to contaminants such as heavy metals and polycyclic aromatic hydrocarbons that become deposited in the virgin oil as a result of the wear and tear of engines, and through combustion and breakdown of additives present in the pure lubricating oil (Usman \& Kayode-Sote, 20I I, p. 160). Although there has been no strong evidence to firmly conclude that waste oil is harmful to human health, the use of protective gear has been encouraged in order to prevent any potential impacts that may result from contact with waste oil (such as eye, skin, and respiratory irritations) or with any component of the waste oil that may be carcinogenic. However, some studies have cited waste oil as having negative impacts on the aquatic and terrestrial environment.

A study conducted in Alaska nine years after the Exxon Valdez oil spill revealed that numerous marine bird species were negatively affected at the population level and have not recovered to the population densities prior to the spill, with persistent oil in the environment cited as the reason for this (Irons \& Kendall, 2000, p. 730). Another study revealed that the toxicity of waste oil had greater effects on the germination, growth, and yield of crops and more specifically, were found to show germination characteristics of stunted growth, yellowing of leaves and death of tips and margins of Arachis hypogea and Zea mays crops, with increasing negative effects from increasing concentrations of waste oil (Abdulhadi \& Kawo, 2006, Pp. 156 \& 159).

In many parts of the world, waste oil continues to pollute the environment due to the absence of controlled, regulated, and ecomonic incentives to properly manage waste engine oil. Many nations have legislation specific to waste oil management as a hazardous waste. For example, in Germany, the disposal of used oil has been carried out according to the guidelines set out in The Used Oil Ordinance since 1986 (Federal Ministry for Economic Cooperation and Development, 2000, p. 7). Likewise, in St. Lucia, used oil is classified under the Marine Pollution Legislation of St. Lucia (St. Lucia Solid Waste Management Authority, 2004, p. 19). Management of used oil in Guyana lacks a structured approach for its appropriate disposal since the Regulations go as far as to exempt used oil and filters from the list of materials considered to be hazardous (Guyana Environmental Protection Agency [EPA], 2000, p. I5).

In an effort to reduce the need for transboundary shipments, Article 4, Section $2 b$ states that "appropriate measures should be taken to ensure the availability of adequate disposal facilities, for the environmentally sound management of hazardous and other wastes" (UNEP, 20I I, p. 2I). Although Guyana has an obligation under the Basel Convention to ensure proper management of hazardous waste, the exemption of waste oil from the list of hazardous wastes under Guyana's Environmental Protection (Hazardous Wastes Management) Regulations 2000 creates uncertainty as to whether the rules governing hazardous waste management are applicable when considering used oil.

The literature available on waste oil management is widespread and demonstrates the level of interest and concern placed on ensuring the process of waste oil management is environmentally 
friendly and where possible economically beneficial. The Basel Convention categorises waste oil as hazardous; as a consequence, concern must be given to the way in which it is handled and disposed. As part of Guyana's obligation under the Basel Convention, the management of waste oil becomes paramount. It is therefore imperative to prevent the entry of waste oil into the environment through efficient and effective waste oil handling, storage, transportation, and disposal practices.

The importance of waste oil management is usually enshrined in legislation, which provides specific guidelines on the management of waste oil from handling to disposal. In most developing countries that lack financing and technologies, there is a lack of detailed guidelines that provide a useful framework for the management of waste oil of any sort, although statutory regulations may generally cover waste oil as a hazardous waste (Federal Ministry for Economic Cooperation and Development, 2000, p. 9). Therefore, there is need for more stringent regulations and guidelines specific to the management of various types of waste oil in developing countries including used engine oil.

\section{Waste Oil Management Methods}

Worldwide increases in vehicle use place added pressure on countries to manage waste engine oil generated as a result of compulsory oil changes at specific time intervals. It therefore means that unless a use is found for this 'waste' product, the volumes stored worldwide will accumulate and increase the risk of accidental spills, or improper disposal methods may be used to get rid of the 'waste'.

A wide range of waste oil management methods that provide an alternative use of the waste oil are presented in the literature, some of which although not environmentally sound, provide a means of disposal of waste oil. It is these types of waste oil management methods - such as use as vermin, termite, and dust suppressants - that should be avoided in an effort to prevent direct or indirect pollution through these uses. Although toxins in used engine oil may take some time to accumulate to critical levels, they have resulted in serious environmental damage in many cases. According to the technical guidelines for the Basel Convention, "the potential impact generated by road oiling on health and the environment are severe enough to discourage or prohibit such practice" (Basel Convention, 1997 p. 9). In Ontario, some lakes were found to be so affected by runoff from roads subjected to road oiling using waste oil, that PCB levels were significantly elevated relative to non-affected lakes (Suns \& Curry et al., 1980 p. I2). In New Zealand, common complaints concerning road oiling included high odour and oil adherence to vehicles (Ministry for the Environment, 2000 p. II).

An analysis of available literature highlights the fact that preferred alternative uses of waste engine oil such as reclamation, refining, and controlled burning are more common in developed nations, and when they exist in less developed countries, they exist on a smaller scale. However, common uses of waste engine oil in developing countries include uses that can have significant negative impacts on the environment.

Although the implementation of environmentally sound waste oil management strategies is necessary, a number of factors hinder the ability of many nations to do so. A Bangkok study concluded that in Asian countries, although waste oil recycling has been practiced for a number 
of years, the practice is still informal and unpopular due to insufficient technical, legislative, and regulatory support (Leong \& Laortanakul, 2003, p. 743). Similarly, some of the weaknesses identified in the management of hazardous and solid wastes in Jamaica included inadequate policy and regulatory frameworks, inadequate enforcement of existing legislation, inappropriate techniques being used at disposal sites and no facilities for storage, and treatment and disposal of hazardous wastes (Planning Institute of Jamaica, 2007, p. 48). The need for sensitising the public of the programmes in place for waste oil collection is seen as important. Lack of awareness or concern for waste oil management was also cited in the literature as a barrier that prevents those generating waste oil from implementing proper management strategies (Yusuf, 2010, p. 36).

In Guyana the situation is a bit more serious: although considered a hazardous waste by the Basel Convention, waste oil is not listed as a hazardous waste and as such is not even indirectly managed by the country's Environmental Protection (Hazardous Wastes Management) Regulations, 2000. In Guyana, it was also stated that the failure to compel generators of waste oil to become registered has hindered the implementation of proper waste management practices (Yusuf, 2010, p. 36). Hence, the need for stringent guidelines governing waste oil management is essential in creating a uniform system for dealing with waste oil in an environmentally sound manner.

\section{Methodology}

\section{Rationale for Selection of Study Area}

Linden is located in Upper Demerara-Berbice (Region 10), approximately $107 \mathrm{~km}$ inland from Guyana's Atlantic Coast on the East and West Banks of the Demerara River. It occupies an area of $140 \mathrm{~km}^{2}$, has a population of about 40,000 and is the main population centre of Region I0. In years past, the main economic activities of Linden were centred on the bauxite industry which developed after the discovery of the mineral in the late 1920s. Although the bauxite industry has contracted it still employs a substantial number of the region's population (Guyana Water Incorporated, 2012).

Linden was selected for this study because, aside from being well known, it is easily accessible and is a central place for many vehicles, especially heavy duty ones that are either on their way into or out of interior locations in Guyana. Although Region 10 has a population of approximately 40,000, the Caribbean Environmental Health Institute (CEHI) Hazardous Waste Inventory Report cited Region 10, of which Linden is the most populated, as the second largest generator of Category Y9 waste from the sale, maintenance and repair of motor vehicles, accounting for approximately $36 \%$ of the total country wide generation (Table I). 
Table I: The Distribution of Y9 Waste by Region for the Sale, Maintenance and Repair of Motor Vehicles Including Retail Sale of Automotive Fuel Sector

\begin{tabular}{|c|c|}
\hline Region & \% of total \\
\hline \hline 2 & 3.95 \\
\hline \hline 3 & 6.75 \\
\hline \hline 4 & 48.62 \\
\hline \hline 5 & $1.5 \mathrm{I}$ \\
\hline \hline 6 & 1.57 \\
\hline \hline 7 & 1.07 \\
\hline \hline 10 & 36.53 \\
\hline
\end{tabular}

Source: CEHI, 2009

\section{Sample Size Selection}

Since the mechanic workshops to be targeted are the small, unregulated ones that are absent from available databases, a reconnaisance survey of the area was conducted during which 15 mechanic shops were identified. Since the sample was so small, a census of the population was taken so as to maintain precision and accuracy.

\section{Research Instruments}

Questionnaires were pre-tested and altered during a pilot study before they were finalised as an instrument of data collection. The questionnaire was chosen because it is a means of obtaning first hand data from the respondents in order to make firm conclusions about the mehanics' management practices. Observational checklists were used to corroborate some responses given by mechanics, such as the general layout of the workshop in relation to living areas, as well as conditions of the area near storage and where oil changes are conducted. This was believed to be important since there is a tendency for persons to deny their involvement in polluting activities. However, there exists some evidence of pollution because of the persistent black residue that remains long after waste oil pollution has occurred.

\section{Data Collection}

This objective was achieved through the use of carefully designed, pretested questionnaires that sought to explore the waste engine oil management practices among the mechanics. The questionnaire was administered via a face-to-face method to minimise the risk of mechanics misunderstanding questions posed and providing incorrect answers. The questionnaire was considered sensitive because waste oil is considered to have significant negative impacts on the environment and, as a result, respondents may be more likely to give an answer which they may believe to be the best response but not necessarily truthful.

\section{Data Analysis}

The descriptive method of data analysis was used to present critical information gathered. Due to the number of open ended questions in the research instrument, descriptive data analysis was selected to describe important phenomenon through reporting and the presentation of graphs and charts. However, in order to ultimately assess the degree of acceptability of the waste oil management practices, a framework setting out the criteria for assessment was created by using 
existing regulations and best practice guidelines from the United States of America and Sri Lanka. The criteria was then used to compare current management practices among the mechanics with those stipulated in the selected guidelines by noting the percentage of mechanics that comply with the guidelines set out in the framework. Consequently, points were awarded based on the degree of compliance stated and observed. In cases where observations were made, the results of the observation were used to judge the degree of compliance with recommended practices, and as such responses from the questionnaire were ignored. On the other hand, responses were considered in cases where observations were not made and the points allocated accordingly. In this way, each parameter was equally weighted. A maximum of 20 points was awarded for each parameter and the possible score out of twenty was calculated based on the percentage of mechanics that complied.

\section{Ethical Considerations and Limitations}

The researcher recognises the importance of respecting the respondents' wishes at all times and therefore ensured that confidentiality was assured and upheld. Due to the nature of the study, some respondents were sceptical about disclosing information for fear of being penalised for improper management practices. Photographs of the storage area were needed and as such created some amount of scepticism on the part of the mechanics/owners of the mechanic workshops. As a result, the assurance of confidentiality was reinforced and permission was sought before photographs were taken. In the cases where respondents could not be persuaded of confidentiality, the wishes of such persons were respected. The researcher also had an ethical obligation to ensure that information released by various entities was used only for the purposes of this survey. Aside from this, all literature used in the compilation of this research paper was cited and referenced appropriately so as to maintain academic integrity.

Availability of information was a limitation; since the small mechanic shops of interest are unregulated, there exists no database from which a list of mechanic shops in Linden could be easily obtained. As a result, the researcher resorted to a reconnaissance survey. Given the fact that snowball sampling had to be used, the possibility exists that a few more mechanic shops may exist that other mechanics may be unaware of. As a result, critical members of the sample population may have been excluded.

\section{Analysis and Discussion}

\section{Handling Practices and Conditions}

The responses revealed a wide range of areas within the vicinity of the mechanic shop where oil changes are conducted. Figure I illustrates that this was done primarily on the floor of the workshop or on the parapet near the workshop. Although the areas where oil changes were conducted varied among the mechanic shops, observations revealed that the surface of the oil changing area was either concrete in nature or an earthen surface. Of the workshops investigated, eight had concrete surfaces as their oil change area, five had soil, and two had a combination of both concrete and soil surfaces (Figure 2). 


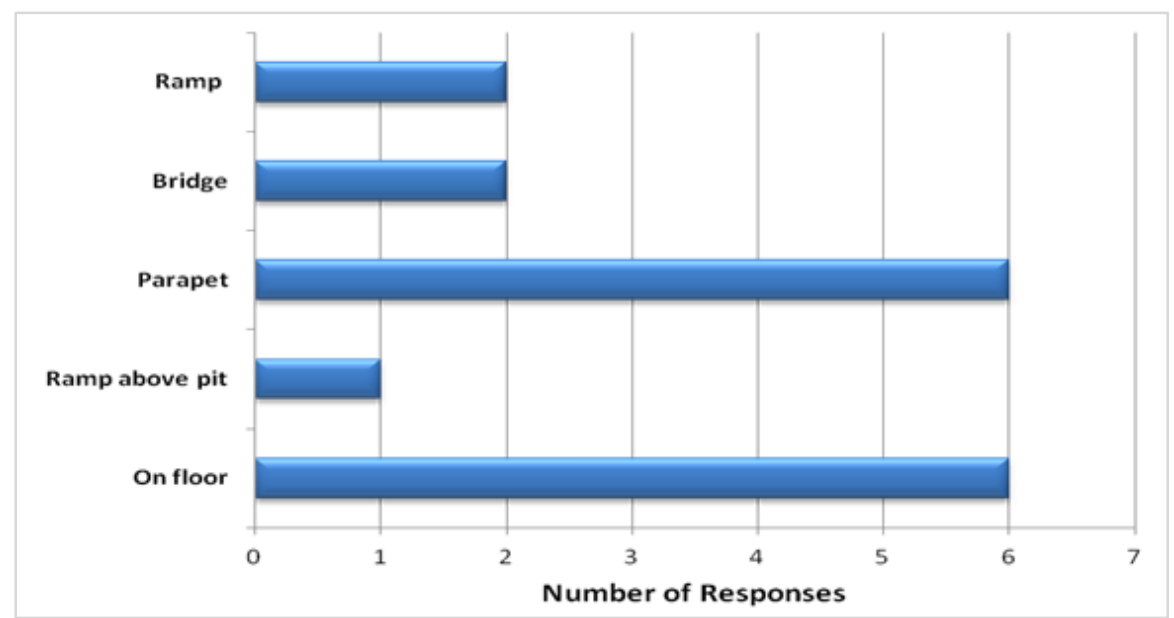

Figure I: Oil Change Locations

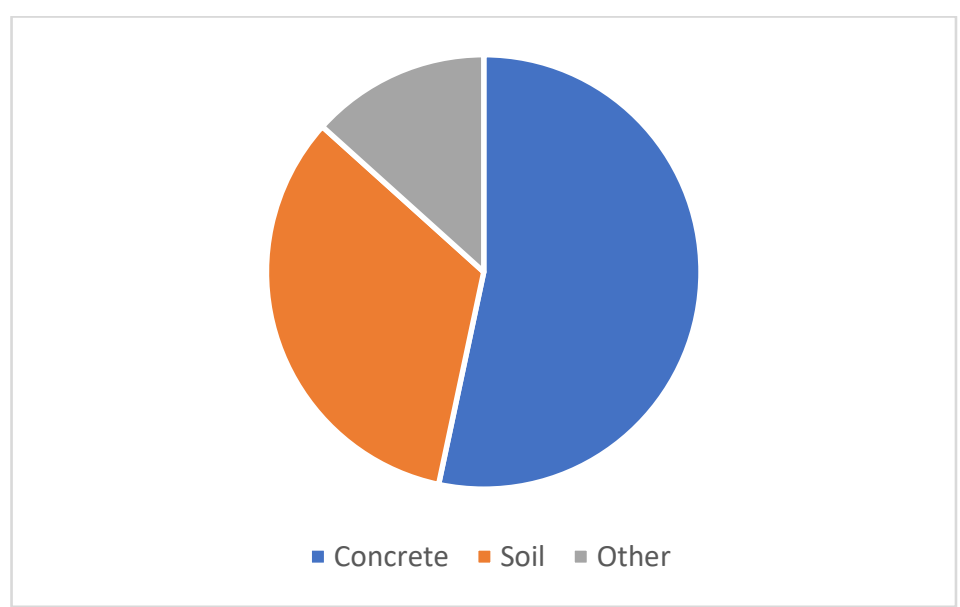

Figure 2: Oil Change Surface Types

All mechanics stated that during oil changes, the oil was drained directly from the motor vehicles into a plastic or metal container with a capacity that ranged between 0.25 to 10 gallons. Aside from this, employees rarely wore protective attire and cited reasons such as comfort, affordability, and personal choice.

\section{Storage Practices and Conditions}

All mechanics reported that before a final choice for disposal was made, waste oil was stored onsite in plastic/metal containers with a capacity of five gallons to forty-five gallons. Although best practice guidelines stipulate that plastics are unsuitable for storing waste oil, this material was more commonly used in comparison to the recommended metal containers (Figure 3). 


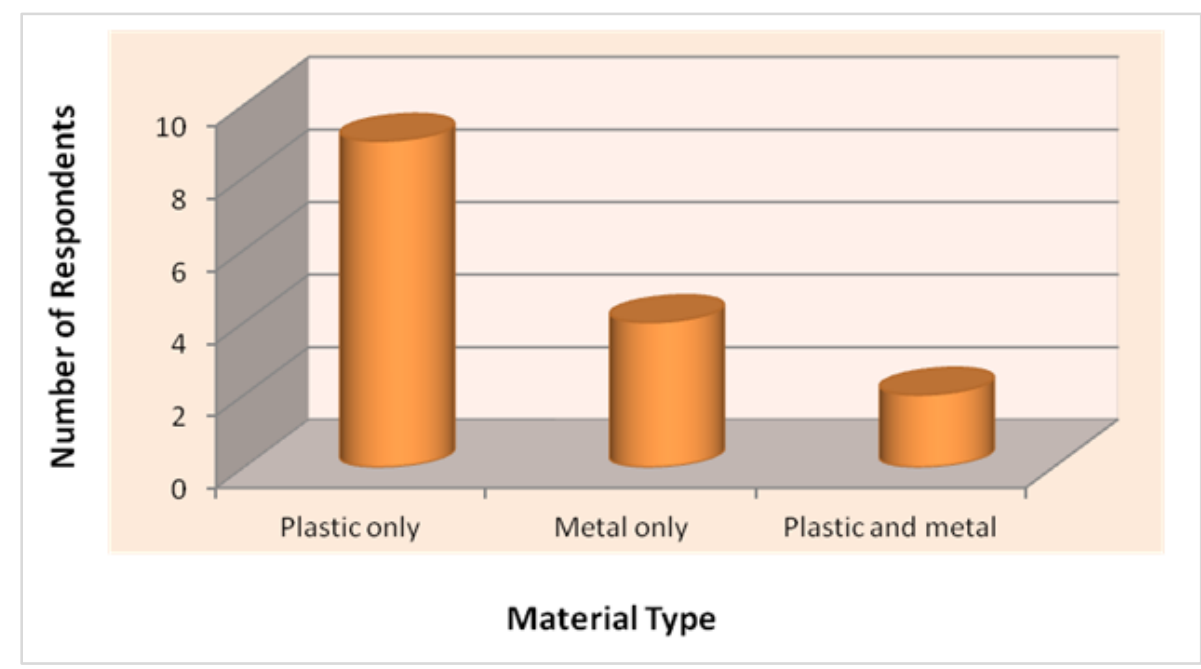

Figure 3: Comparison of Oil Storage Containers

According to the data gathered, no respondent labelled storage containers, although 12 of them kept storage containers covered and in a designated storage area in cases where there was one. While this was so, three respondents mixed their waste oil with water and combined all kinds of waste oil generated in one storage container. Measures taken to remedy accidental spills during storage (as well as during oil changes) mainly involved the use of sand or sawdust as an absorbent. Guidelines governing the management of waste oil state that absorbent materials should be handled carefully before disposal by removing the oil and ensuring that the absorbent does not contain hazardous components before disposal. In cases where they do contain hazardous contaminants, they must be taken to a hazardous waste facility to be disposed; otherwise, they may be disposed at a landfill site (USEPA, 1994, p. 19). Unfortunately, this study revealed that the final fate of the absorbent used was either on-site dumping or garbage bins disposal. This highlights the fact that although a conscious effort is being made to ensure the oil change and storage areas were free of oil residue, the same degree of caution was not exercised to avoid further environmental damage at final disposal of absorbents.

The length of time during which waste oil was stored varied tremendously ranging from a mere one day to as much as one year. It is believed that although waste oil storage is currently practically recommended by the Guyana EPA, the longer waste oil is stored, the higher the chances of accidental spillage. Secondly, because waste oil storage capacity is finite and there is a market for waste oil, all respondents have opted to get rid of their stored waste oil by a number of ways, which included dumping (I mechanic).

\section{Disposal Practices and Conditions \\ Dumping}

Although observations revealed evidence of waste oil spillage in the environs of a few mechanic shops, only one mechanic reported that he dumped waste oil because his storage capacity was limited and the waste oil was also being used as a weed suppressant. He stated that this practice was a new one and has resulted because the market for waste oil has been taken over by persons residing closer to the interior who make waste oil available to the chainsaw operators at a much cheaper cost than his sale price. He stated that approximately six pints ( 0.75 gallons) of waste oil was being dumped on the vegetation behind his workshop on a daily basis. Despite this activity, 
he believes that such a practice had no significant negative impacts on the environment and although it destroyed vegetation, it was his aim to do so.

\section{Given Away/Sold/Reused}

The waste oil was given away or sold primarily to chainsaw operators for the purpose of lubricating their chainsaws (Figure 4). This finding was similar to that of Yusuf (2010) where waste oil generated was sold mainly to chainsaw operators. Hence, irrespective of location, this seems to be a popular alternative use for waste oil in Guyana. In cases where the waste oil was sold, mechanics interviewed received between $\$ 110$ and $\$ 300$ per gallon. Although one mechanic stated that he sold as much as 90 gallons of waste oil weekly, six sold smaller quantities (5-45 gallons) at frequencies ranging from fortnightly to every six months. Despite the fact that accumulation of waste oil on-site increases the chances of large scale spills, waste oil should be handled as little as possible since the more the used oil is transferred from one storage container to another or transported around the facility, the greater the potential for spills (USEPA, 1994, p. 34). Although it is seen as a potential business, the sale of waste oil for use in the timber industry is not environmentally sound and as such is not approved by the Environmental Protection Agency.

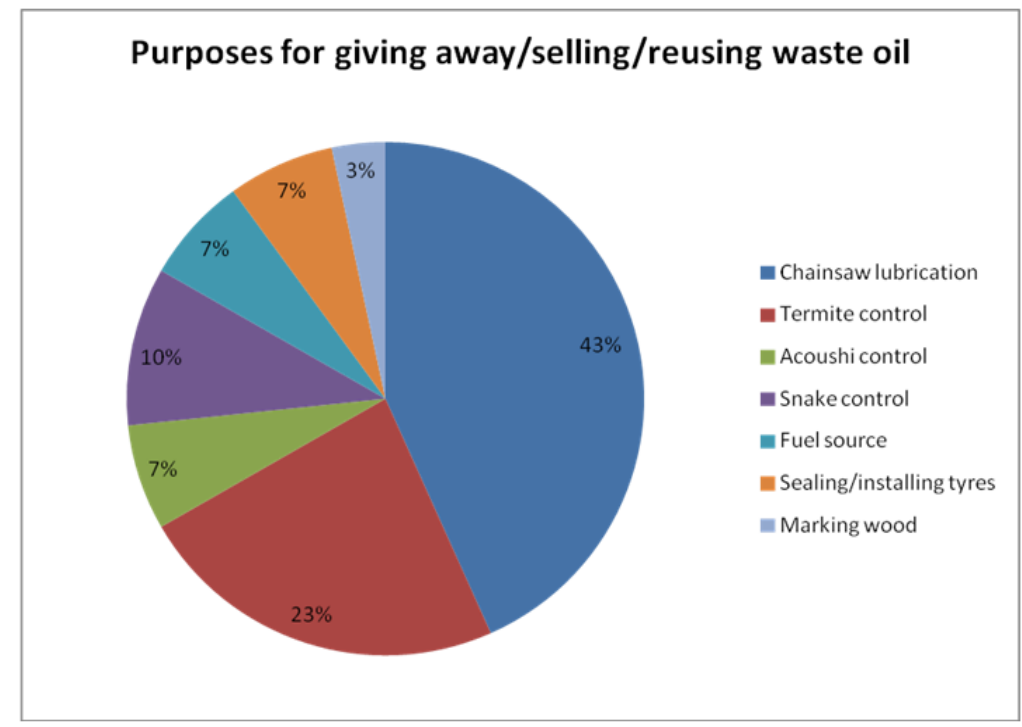

Figure 4: Purposes for Giving Away/Selling/Reusing Waste Oil

As shown in Figure 4, a large proportion of respondents (40\%) reportedly give away waste oil generated to residents in the community for minor uses, which mainly encompassed various forms of pest control (which, as previously stated, is unapproved and therefore not recommended by the Guyana EPA). Only one generator stated that he reused the waste oil. However, the purpose for which he did so was similar to a large number of other users since he stated that he had a timber operation in the interior.

\section{Transporting}

Fourteen of the fifteen mechanics (93.3\%) stated that their waste oil was uplifted by collectors. There was, however, a lone mechanic who reused his waste oil and as such undertook the responsibility of transporting the waste oil. The oil was transported in either 45 gallon plastic 
drums or 5 gallon plastic bottles fortnightly using a pickup truck. Based on the information previously gathered, the monthly volume transported by this individual should amount to approximately 72 gallons since he stated this as the amount of waste oil he generated on a monthly basis. The waste oil is transported to an interior location for the purpose of being used as a lubricant for chainsaws. The mechanic also took preventative measures to avoid the spilling of waste oil by securely strapping the containers so as to limit the possible movement that can occur. In spite of this, in cases where spills occurred, the vehicle was taken to a car wash and cleaned.

\section{Observations}

Specific observations were made at the mechanic shops so as to draw conclusions and corroborate some of the information obtained from the questionnaires. It was observed that only one mechanic shop was completely enclosed while four were in unshaded yard or parapet areas, and ten were in shaded parapet or yard areas. While five mechanic shops were detached from any buildings, ten were in close proximity to living quarters. However, fivfive shops were closely joined to the living area and 5 were distinctly separate from the living areas.

An inspection of the storage area showed that all workshops had storage containers present, of which none was labelled. At two mechanic shops, containers showed signs of leakage while the containers at 13 shops appeared structurally intact. There was also no spill containment in the storage area of any mechanic shop which had surfaces comprised of soil (6), metal (I), sawdust (I), and concrete (7). Oil residue was visible on the ground of the storage area in nine mechanic shops, while the storage area at the remaining six shops had no oil residue visible. Of the 3 mechanic shops with drains near the storage area, oil was visible in one drain. The oil change area of eight mechanic shops showed no sign of oil residue on the ground compared to the oil change area at seven shops where oil residue was visible. Oil was visible in the drains near the oil change area of two mechanic shops. Observation of the employees' attire revealed that only at one mechanic shop was there an indication of safety attire used, which in this case was a pair of safety boots worn by one employee.

\section{Assessment of Management Practices}

In assessing the management practices, although the responses of the questionnaires revealed compliance with best practices for used oil management, observations showed that the degree of compliance was less than stated. The overall result of the assessment is seen in Table 2.

Table 2: Results of Assessment of the Mechanics in Linden Management Practices

\begin{tabular}{|l|l|l|l|}
\hline Practice/condition & Points gained & Total points & Compliance (\%) \\
\hline Handling & 1.34 & 20 & 6.70 \\
\hline Storage & 88.00 & 160 & 55.00 \\
\hline Disposal & 0.00 & 60 & 0.00 \\
\hline Emergency Response & 37.32 & 60 & 62.20 \\
\hline Overall Practices & $\mathbf{1 2 6 . 6 6}$ & $\mathbf{3 0 0}$ & $\mathbf{4 2 . 2 2}$ \\
\hline
\end{tabular}

Generally, the respondents' management practices can be viewed as substandard since less than $50 \%$ of mechanics complied with the best practice requirements. The poor compliance in handling and disposal of waste oil, was mainly responsible for the waste oil management 
practices among mechanics in Linden being categorised as unsatisfactory. Emergency responses are fairly well adhered to, and as such, contributed positively to the respondents' overall practices. It is also noted that disposal practices exercised among the mechanics were extremely poor, since none complied with disposal practices set out in suggested guidelines. This can be attributed to the lack of such recommended disposal facilities within the country.

\section{Conclusion}

The overall assessment of the waste oil management practices among Linden mechanics indicated that although the storage practices and emergency response measures were satisfactory, the poor handling and disposal practices of the mechanics contributed to their overall practices being categorised as unsatisfactory. The disposal methods currently employed by the mechanics, such as use for chainsaw lubrication, and termite, and snake and acoushi ants control, conflict with best practices for waste oil management and as such are not recommended by the Guyana EPA. At present, the Guyana EPA recommends that waste oil should be stored in an environmentally appropriate manner until there is a facility at which it can be disposed.

\section{Recommendations}

- There is need for legislation/regulations that specifically address the management of waste oil in such a manner that they clearly set out guidelines for its management.

- The activities of waste oil generators should be monitored to ensure that practices are being conducted in accordance with the guidelines set out in the legislation, irrespective of the volume of waste oil generated.

- Management of the waste oil must also include materials that may be contaminated by waste oil, such as absorbents used to remedy spills and oil filters.

- The need for improved management practices must be commensurate with improved disposal facilities/options in Guyana.

- There needs to be an assessment of the waste oil management practice among other users who are in receipt of waste oil, such as chainsaw operators and residents, to determine environmental impacts of these practices. An attempt to quantify the volume of waste oil devoted to minor uses can be useful in attempting to assess the potential environmental impact.

\section{Acknowledgements}

Thanks are extended to the mechanics of Linden for their participation in this study, and to officers of the EPA, BOSAI Guyana Minerals Inc., the Linden Town Council, Ministry of Local Government, MACORP and GUYSUCO for their valuable contributions to this research. 


\section{References}

Abdulhadi, S.K. and Kawo, A.H., 2006. The effects of used engine oil pollution on the growth and yield of Arachis hypogea $L$ and Zea mays L. African Scientist, 7 (3), pp. I55-160. Available at: <http://www.klobex.org/journals/afs/afs7/afs730906026.pdf> [Accessed I January 2012].

Basel Convention, 1997. Technical guidelines on used oil re-refining or other re-uses of previously used oil. Available at: <http://archive.basel.int/meetings/sbc/workdoc/old\%20docs/tech-y8.pdf> [Accessed I4 February 2010.

Bourgeois, M., n.d. Used oil management: International experiences and approach for Colombia. International Fair and Seminar - Solid and Hazardous Waste Integral Management XXI century. Available at: <http://www.bvsde.paho.org/bvsacd/acodal/xxiii.pdf> [Accessed 25 November 20I I].

Caribbean Environmental Health Institute (CEHI), 2009. National hazardous waste inventory study for Guyana.

Federal Ministry for Economic Cooperation and Development, 2000. Environmentally oriented management of used oils. Available at: <http://www.gtz.de/de/dokumente/enenvironmentally-oriented-management-used-oil.pdf> [Accessed 10 March 2012].

Guyana Environmental Protection Agency, 2000. Environmental protection (hazardous waste management 2000) regulations. Available at: <http://www.epaguyana.org/index.php/regulations> [Accessed 17 December 20II].

Guyana Water Incorporated, 2012. Water safety plan. Available at: <http://www.gwiguyana.com/?q=node/I I 2> [Accessed 26 December 20I2].

Irons, D.B. and Kendall, S.J., 2000. Nine years after the "Exxon Valdez" oil spill: Effects on marine bird populations in Prince William Sound, Alaska. The Condor, 102 (4), Pp. 723737. Available at: <http://www.cof.orst.edu/cof/teach/fs599_08/Readings/new.Irons\%20etal_2000_9\%20y ears\%20after\%20EVOS\%20effects\%20marine\%20bird\%20population\%20in\%20PWS_C ONDOR.pdf> [Accesed 2I December 20I I].

Leong, S.T. and Laortanakul, P., 2003. An environmental approach for used oil management in Asian cities: Bangkok's experience. Journal of Environmental Sciences, I5 (6), pp. 734-743. Available at: <http://iospress.metapress.com/content/rk5nl4f874w3jbt6/fulltext.pdf> [Accessed I4 February 2012].

Ministry for the Environment, 2000. Used oil recovery, reuse and disposal in New Zealand: Issues and options. Available at: <http://www.mfe.govt.nz/publications/waste/used-oil-recoverydec00.pdf> [Accessed I April 20I2].

Nixon, H. and Saphores, J., n.d. Used oil policies to protect the environment: An overview of Canadian experiences. Available at: <http://www.uctc.net/papers/666.pdf> [Accessed I5 December $20 \mathrm{II}$.

Planning Institute of Jamaica, 2007. Management of hazardous and solid wastes in Jamaica.

Available at:

<http://www.pioj.gov.jm/Portals/0/Sustainable_Development/Management_of_Wastes.pd $f>$ [Accessed I0 March 20I2].

St. Lucia Solid Waste Management Authority, 2004. Strategy on management of used oil. Available at: <http://www.stlucia.gov.lc/nemp/guidelines/OilStrategy.pdf> [Accessed 25 November 2012]. 
Suns and Curry et al., 1980, The effects of road oiling on PCB accumulation in aquatic life. Available at: <http://www23.us.archive.org/details/effectsofroadoil00suns> [Accessed I April 20I2]

United Nations Environment Programme, 20I I. Protocol on liability and compensation for damage resulting from transboundary movements of hazardous wastes and their disposal. Available at: http://www.basel.int/Portals/4/Basel\%20Convention/docs/text/BaselConventionTexte.pdf> [Accessed I 4 January 20I3].

United States Department of Energy, 2006. Used oil re-refining study to address energy policy Act of 2005 Section 1838. Available at: <http://fossil.energy.gov/epact/used_oil_report.pdf> [Accessed 2I December 20II].

United States Environmental Protection Agency, 1994. Environmental regulations and technology: Managing used motor oils. Available at: http://nepis.epa.gov/Exe/ZyNET.exe/30004O7I.TXT!ZyActionD=ZyDocument\&Client= EPA\&Index $=|99|+$ Thru $+\mid$ 994\&Docs $=\&$ Query $=\&$ Time $=\&$ EndTime $=\&$ SearchMethod $=\mid \&$ TocRestrict $=$ n $\&$ Toc $=\&$ TocEntry $=\& Q$ Field $=\& Q$ Field Year $=\& Q$ FieldMonth $=\& Q$ FieldDay $=$ \&IntQFieldOp $=0 \&$ ExtQFieldO $p=0 \& X m \mid$ Query $=\&$ File $=D \% 3 A \% 5$ Czyfiles\% 5 CIndex $20 \mathrm{Da}$ ta\%5C9I thru94\%5CTxt\%5C000000 I3\%5C30004O7l.txt\&User=ANONYMOUS\&Passw ord=anonymous\&SortMethod $=\mathrm{h} \% 7 \mathrm{C}$ -

\&MaximumDocuments $=\mid \&$ FuzzyDegree $=0$ \& ImageQuality $=r 75 \mathrm{~g} 8 / \mathrm{r} 75 \mathrm{~g} 8 / \mathrm{x}|50 \mathrm{y}| 50 \mathrm{~g} \mid 6 / \mathrm{i} 42$ $5 \&$ Display $=p \% 7 C f \& D e f S e e k P a g e=x \&$ SearchBack $=Z y$ ActionL\&Back $=Z y$ ActionS\&BackDes $c=$ Results\%20page\&MaximumPages $=\mid \& Z y$ Entry $=\mid \&$ SeekPage $=x \& Z y P U R L[$ Accessed I April 20I2].

Usman, M., and Kayode-Sote, O.G., 20II. Reclamation of used lubricating oils. Petroleum and Coal 53 (2), pp. I59-166. Available at: <http://www.vurup.sk/sites/default/files/downloads/pc_2_20II_usman_II6_0.pdf> [Accessed 16 December 2012].

Yusuf, T., 20I0. An investigation of the disposal methods of waste engine oil generated from mechanic workshops in Georgetown. Unpublished BSc research project, University of Guyana. 